\title{
Effect of percutaneous transluminal coronary angioplasty on oxidants and antioxidants in patients with coronary artery disease
}

\author{
Ranjeet U. Jadhav', G. J. Belwarkar ${ }^{2, *}$, P. E. Jagtap ${ }^{3}$, S. P. Dhonde ${ }^{4}$, N. S. Nagane ${ }^{5 .}$ \\ ${ }^{1}$ PG Student, ${ }^{2}$ Associate Professor, ${ }^{3}$ Professor \& HOD, ${ }^{4,5}$ Professor, Dept. of Biochemistry, Bharati Vidyapeeth Deemed \\ University Medical College and Hospital, Sangli, India
}

*Corresponding Author:

Email: gbelwalkar@yahoo.com

Received: $14^{\text {th }}$ December, 2017

Accepted: $07^{\text {th }}$ March, 2018

\begin{abstract}
Introduction: Percutaneous transluminal coronary angioplasty (PTCA) has become a common intervention in coronary artery disease $(\mathrm{CAD})$, relieving symptoms such as angina and improving myocardial function. There is short term injury to the heart after PTCA; which can take in the form of reperfusion arrhythmias or myocardial stunning or both. Production of oxygen derived free radical potentially cytotoxic species which can be formed may be controlled by naturally occurring antioxidant defence. In this study we investigated the alterations in oxidative and antioxidative status after PTCA by estimating Malondialdehyde (MDA) as marker of oxidative stress, Superoxide Dismutase (SOD) and vitamin C for antioxidant status and myocardial cell damage by Creatine Phosphokinase total (Cpk-total) and Creatine Phosphokinase-MB (Cpk-MB).

Materials and Methods: 120 patients of CAD, subjected to PTCA were included in the study. MDA, SOD, Vitamin C, Cpk total and Cpk-MB levels were measured after PTCA in patents.

Result: There were increased levels of SOD \& Cpk-total, $4.94 \pm 0$. Units / $\mathrm{ml} \& 119.46 \pm 40.51 \mathrm{U} / \mathrm{L}$, (p < 0.001), respectively, in patients after PTCA. SOD \& Cpk-total are statistically highly significant. MDA was $6.01 \pm 1.22 \mathrm{nmole} / \mathrm{ml}$, considerably decreased \& it is statistically significant ( $p<0.001)$. Vitamin C \& Cpk-MB were $0.88 \pm 0.32 \mathrm{mg} / \mathrm{dl} \& 13.62 \pm 6.17 \mathrm{U} / \mathrm{L}$ (p > $0.05)$, borderline increased. They are statistically insignificant.

Conclusion: These findings suggest that cardial lipo peroxidation may be common event following brief episodes of myocardial ischemia and support a role for antioxidant therapy in patients after PTCA.
\end{abstract}

Keywords: Percutaneous Transluminal Coronary Angioplasty, Oxidative Stress, Antioxidant.

\section{Introduction}

The prevalence of cardiovascular disease has been increasing worldwide. Coronary artery disease constitutes the majority of these cardiovascular diseases. The rupture of luminal plaques, which is consists of cholesterol and lipids, lead to the release of material stimulating platelets activation and thrombin formation. As a result, a thrombus limiting blood flow is formed. ${ }^{1}$

Percutaneous transluminal coronary angioplasty (PTCA) has become a common intervention in coronary artery disease, relieving symptoms such as angina and improving myocardial function. There is also an acute or short term injury to the heart after PTCA; which can take in the form of reperfusion arrhythmias or myocardial stunning or both. One possible mechanism to account for the latter insult may be that PTCA induces a reperfusion injury by the production of toxic oxygen derived free radicals (ODFRs) and other metabolites, such as the superoxide anion and the hydroxyl radicals. Production of these potentially cytotoxic species which can be formed from hydrogen peroxide may be controlled by naturally occurring antioxidant enzymes. The reperfusion injury hypothesis is supported by previous studies. Lipid peroxides are produced by PTCA by successful thrombolysis in acute myocardial infarction. ODFRs likely to act on the endothelium as the primary target organ. A damaged endothelium may not function correctly. ${ }^{2}$

Increases in oxidants and decreases in antioxidants may impair the oxidative/antioxidative balance towards the oxidative status. Increased oxidative status may initiate lipid peroxidation in cell membrane, damage membrane proteins or cause DNA fragmentation, resulting in loss of heart contractile function and severe myocardial cell damage. ${ }^{3}$

Studies have been investigating oxidative stress after PTCA yielded conflicting results. In this study we investigated the alterations in oxidative and antioxidative status after PTCA by estimating MDA as marker of oxidative stress, SOD and vitamin $\mathrm{C}$ for antioxidant status and myocardial cell damage by Cpktotal and Cpk-MB.

\section{Materials and Methods}

First part of our project was published in same journal of July - September issue. The present study was performed in department of Biochemistry in association with Cardiology department Bharati Vidyapeeth Deemed University Medical College and Hospital, Sangli. The study protocol was confirmed by the Institutional Ethical Committee. Inclusion criteria were coronary artery disease patients had indications of 
PTCA like acute ST - elevation myocardial infarction, non ST - elevation, acute coronary syndrome, unstable angina, stable angina, arrhythmia \& high risk stress test finding. Exclusion criteria were lack of patient's consent for study, chronic kidney injury, chronic inflammatory disease, heart failure, recent major surgical procedure, use of diuretics, alcoholic and liver diseases. Patients with prior myocardial infarction, in past 48 hours before admission and cardiomyopathy were also excluded. Informed consent was obtained from all subjects. We have compared the results of pre (before) PTCA with post (after) PTCA of coronary artery disease patients.

All 120 patients had coronary artery disease \& required PTCA. Their average range age was 41-60 years. Out of 120 patients 78 were males and 42 were females. Blood samples were taken from each patient, after PTCA. Blood samples were immediately analysed after collection of blood. Malondialdehyde (MDA) were measured by Kei Satoh method, ${ }^{4}$ Superoxide Dismutase (SOD) by Marklund and Marklund method, ${ }^{5}$ Vitamin $\mathrm{C}$ by Ayekaw method, ${ }^{6}$ Creatine Phosphokinase Total (Cpk total) by NAC-activated kit method $^{7}$ and Creatine Phosphokinase-MB (Cpk-MB) IFCC kit method. ${ }^{7}$ All parameters were estimated in serum. Analysis of the data was carried out by using ANOVA and difference between controls and patients was determine by student ' $\mathrm{t}$ ' test.

\section{Result and Discussion}

MDA was significantly decreased in post PTCA patients as compared to pre PTCA patients $(\mathrm{p}<0.001)$. It is statistically highly significant. SOD was significantly increased in post PTCA patients as compared to pre PTCA patients $(\mathrm{p}<0.001)$. It is statistically highly significant. Vitamin $\mathrm{C}$ was not significantly increased in post PTCA patients. It is statistically insignificant $(\mathrm{p}>0.05)$.

A comparison of this increased with the influx of oxygenated blood was confirmed by a relationship with the situation in pre PTCA patients. Subsequent decrease of MDA level, which even dropped below the initial level after $6 \mathrm{hr}$. of PTCA, may be caused the activation of antioxidant mechanisms, especially the enzymatic antioxidants. Free radical were increased suddenly after reperfusion, the activity of antioxidant defence system was followed. SOD may be over expressed and catalyses elimination of reactive oxygen species. Hence enzymatic antioxidant, SOD significantly increased in post PTCA patients. ${ }^{8}$ But non enzymatic antioxidant vitamin $C$ was not increased significantly.

Hakan Tas $M$ et al, ${ }^{9}$ Ramon Rodrigo et $a 1,{ }^{10}$ Kesmarky $\mathrm{G}$ et al, ${ }^{11}$ and Naranjan S Dhalla, ${ }^{12}$ found similar results with our study.

Cpk - Nac was significantly increased in post PTCA patients as compared to pre PTCA patients ( $\mathrm{p}<$ $0.05)$. It is statistically significant.

It is due to myocardial necrosis in this setting could result from embolization of plaque, microparticles debris of intravascular friable material, clots or cholesterol crystal. Also minor in lab complications are all conditions that can cause small zones of necrosis because of sudden mismatch between metabolic requirements of the myocardium and coronary blood flow. ${ }^{13}$

Cpk - MB was increased in post PTCA patients; statistically it is insignificant $(p>0.05)$. We observed that repeated ischemia reperfusion episodes may occur injury which damage to the myocardium following blood restoration after critical period of coronary occlusion. However Cpk-MB was borderline increased in post PTCA patients. ${ }^{14}$

We found that negative correlation between MDA and SOD in post PTCA patients. Statistically it is significant. $(r=-0.308)$

Severity of oxidative stress in the form of MDA was negatively correlated with enzymatic antioxidant, SOD. The higher activity of antioxidant enzymes may be compensatory regulation in response to increased oxidative stress. As a result in post PTCA patients MDA was decreased and SOD was increased.15

We also found that positive correlation between MDA and Cpk-MB in pre PTCA patients, statistically it is significant $(\mathrm{r}=0.147)$. But there was no correlation found between MDA and Cpk-MB in post PTCA patients $(\mathrm{r}=-0.071)$.

Microvascular structural damage may be directly related to the degree of oxidative stress and lipid peroxidation. Cpk-MB is also released from damaged myocardial cells. ${ }^{8,16}$

\section{Conclusion}

Our findings suggest that cardial lipo peroxidation may be a common event following brief episodes of myocardial ischemia and support a role for antioxidant therapy in patients with ischemic heart disease. Hence we also suggest that antioxidant therapy will be benefitted in post PTCA patients. 
Table 1: Comparison between Serum MDA, SOD, Vitamin C, Cpk Nac \& Cpk-MB in pre and post percutaneous transluminal coronary angioplasty patients

\begin{tabular}{|c|l|c|c|c|c|}
\hline S.No. & Parameter & $\begin{array}{c}\text { Pre PTCA } \\
\text { Patients } \\
\mathbf{n = 1 2 0}\end{array}$ & $\begin{array}{c}\text { Post PTCA } \\
\text { Patients } \\
\mathbf{n = 1 2 0}\end{array}$ & p value & Significance \\
\hline 1 & MDA nmole/ml & $9.42 \pm 1.07$ & $6.01 \pm 1.22$ & 0.000 & Highly significant \\
\hline 2 & SOD Units/ml & $3.19 \pm 0.45$ & $4.94 \pm 0.93$ & 0.000 & Highly significant \\
\hline 3 & Vitamin C mg/dl & $0.88 \pm 0.32$ & $0.90 \pm 0.36$ & 0.728 & Not significant \\
\hline 4 & Cpk Nac U/L & $105.95 \pm 45.44$ & $119.46 \pm 40.51$ & 0.016 & Highly significant \\
\hline 5 & Cpk-MB U/L & $12.20 \pm 6.03$ & $13.62 \pm 6.17$ & 0.057 & Not significant \\
\hline
\end{tabular}

\section{References}

1. Hakan TM, Kalkan ME, Aksakal E, Simsek Z, Bakirci EM. et al, "Oxiadtive and antioxidant status successful percutaneous transluminal coronary angioplasty in acute myocardial infarction". J Clin Trail Cardiol 2014);1(1),4. http://dx.doi.org/10.15226/2374-6882/1/1/00103.

2. Andrew B, Harvey M, Gillian B, Simon M, Sarah U et al. Free radicals, antioxidant and endothelial cell damage after percutaneous transluminal coronary angioplasty. Coronary Artery Disease. 1993;4(10):905-10.

3. Mustafa G, Ali Y, Recep D, Remzi Y, Altan K. et al, "The effect of coronary angioplasty on oxidative and antioxidative status". Turk Kardiyol Dern Ars- Arch Turk Soc Cardiol 2007;35(1):21-7.

4. Mohammad HS, Mohammad AU, Mohammad AA, Mohammad SI, Shalahuddin Q, Shelina FS et al, "Serum Antioxidant Vitamins and Malondialdehyde Levels in Patients with Obsessive-Compulsive Disorder" J Psychiatry (2012)15 (1):10-4.

5. Yogesh G, Deepmala D, Surwase SP, Urjita Z, “ Study of the Serum Superoxide Dismutase Levels in Smoking and Non-Smoking Patients with COPD” International Journal of Recent Trends in Science And Technology (2013) ISSN 2277-2812 E-ISSN 2249-8109,5(3),121-6.

6. Aye Kyaw, " A simple colorimetric method for ascorbic acid determination in blood plasma" Clinica Chimica Acta (1978) 86(2):153-7.

Burtis CA, Ashwood ER, editors. Tietz Textbook of clinical chemistry. $2^{\text {nd }}$ ed. W.B. Saunders Company (1994) p.798-809.

7. Muzakova V, Kandar R, Vojtisek P, Skalicky J, Cervinkova Z. Selective antioxidant enzymes during ischemia/reperfusion in myocardial infarction. Physiological Res.2000;49:315-22.

8. Akila, Benedicta D'souza, Prashant V, Vivian D. Oxidative injury and antioxidants in coronary artery bypass graft surgery: Off-pump CABG significantly reduces oxidative stress, Clinica Chimica Acta 2007;375:147-52.

9. Ramon R, Matias L, Felipe F, Daniel H. Molecular basis of cardioprotective effect of antioxidant vitamins in myocardial infarction. Biomed Research International. Available from http://dx.doi.org/10.155/2013/437613.

10. G. Kesmarky, K. Toth, G. Vajda, L. habom, R. Halmosi et al. Hemorheological and oxygen free radical associated alterations during and after percutaneous transluminal coronary angioplasty, Clinical Hemorheology and Microcirculation.2001,24:33-41.

11. Naranjan S D, Adel B E, Tomoji H, Naoki M. Status of myocardial antioxidants in ischemia reperfusion injury. Cardiovascular Research 2000;47:446-56.

12. Alaa E, Eric J, Patric L, Shelly K, Stephen G. Significance of mild transient release of creatine kinase-
MB fraction after percutaneous coronary intervention. Circulation. 1996;94:1528-36.

13. Mustafa G., Ali Y., Recep D., Remzi Y., Altan K. et al. The effect of coronary angioplasty on oxidative and antioxidative status. Turk Kardiyol Dern Ars- Arch Turk Soc cardiol. 2007;35(1):21-7.

14. Yuksel K, Aysegul C, Nihat S, Halit D, Hamit H et al. Correlations between oxidative DNA damage, oxidative stress and coenzyme Q10in patients with coronary artery disease. Int. J. of Medical Science. 2012;9(8):621-6.

15. Fethi AbedAG. Significance of total creatine kinase and creatine kinase MB levels in patients with acute myocardial infarction. Int. J Bio Med Res.2011; 2(3):7625. 